\title{
The influence of start-stop transient velocity on the friction and wear behaviour of a hyper-eutectic Al-Si automotive alloy
}

\author{
J. C. Walker*, T. J. Kamps, R. J. K. Wood \\ National Centre for Advanced Tribology at Southampton (nCATS), Highfield Campus, Southampton, SO17 1BJ, UK \\ *j.walker@soton.ac.uk Tel: +44 2380593761 Fax: +442380 593016 \\ Received Date Line (to be inserted by Production) (8 pt)
}

\begin{abstract}
As worldwide automotive ownership is set to exceed 2 billion vehicles by 2030 [1], environmental and economical pressures on the automotive industry mean there is a trend to reduce harmful greenhouse gas emissions whilst simultaneously improving fuel economy. The use of electrical hybrid, start-stop idling and materials light-weighting are some of the technological solutions which can offer efficiency savings, however their combined use in a tribological context is less well understood. Interruption of piston sliding as a result of start-stop technology will simultaneously interrupt fluid film lubrication at the ring/liner interface. This could have implications on the friction and wear behaviour of Al-Si cylinder blocks, where scuffing can be an issue. In order to determine the effect of a start-stop velocity cycles on the lubricated friction and wear behaviour of a hyper-eutectic Al-Si liner, an interrupted reciprocating laboratory tribometer test programme was developed based upon the European Urban Cycle standard. Refined cast iron piston ring segments were slid at $23 \mathrm{~Hz}$ frequency, $4 \mathrm{MPa}$ nominal contact pressure and $25 \mathrm{~mm}$ stroke length against a conformal honed Alusil cylinder liner segment. Regular velocity interruptions at 60s intervals did not significantly inhibit the dynamic friction behaviour between the liner and the cast-iron piston ring segment, indicating that lubricant additive function was not significantly inhibited. However contact potential and FIB-SIMS depth profiles indicated that antiwear tribo-film thickness was reduced as a result of start-stop cycling. Mass loss from the piston ring was also notably higher as a result of the interruption of elasto-hydrodynamic lubrication causing boundary conditions at re-start and subsequent 2-body abrasion by harder protruding Si particles. Specific wear rates for the Al-Si liner as a result of start-stop velocities were surprisingly lower compared to uninterrupted tests and was believed to be due to faster running-in of the piston ring surface. These results are discussed in terms of the viability of Al-Si as engine materials running start-stop technology.
\end{abstract}

Keywords: FIB-SIMS; Al-Si; Start-Stop; Tribo-film; Lubricated Sliding; Transient Velocity

\section{Introduction}

For the last decade global automotive manufacturers have implemented an array of technological improvements in order to reduce harmful greenhouse gas emissions as well as improve fuel economy. These have included the introduction of hybrid vehicles that draw power from an internal combustion engine and an electrically charged supply, as well as the use of automatic engine controlled start-stop technology when vehicles are stationary. Recent reviews have suggested that implementation of start-stop technology could advocate between 3-10\% efficiency savings per vehicle [2], with the additional possibility of up to $20 \%$ saving in $\mathrm{CO}_{2}$ emissions [3]. In addition, the use of light-weighting technology

*Corresponding author. Tel.: +44 2380 592371; fax: +44 2380595167.

E-mail address:j.walker@soton.ac.uk (John Walker) 
such as aluminium or magnesium chassis frames, body panels and engine blocks have also ensured that greenhouse gas emission due to excess inertial mass is minimised [4]. Such savings and efficiency gains are often measured and bench marked by the use of standard test cycles such as the European Urban and Extra Urban Cycles [5].

Whilst these technologies are mutually complimentary in terms of their environmental benefits, their simultaneous use in a tribological context is less well understood, beyond perhaps an appreciation that start-stop can produces conditions of lubricant starvation between contacting surfaces and local temperature rise $[6,7]$. The use of aluminium as a cylinder facing material in the engine block requires that significant amounts of silicon are introduced into the alloy composition in order to precipitate primary and secondary Si colonies from a saturated matrix to act as the bearing contact surface against the piston ring pack, thus protecting the softer aluminium from scuffing [8-11]. Whilst this technology has been fairly well developed for mass produced consumer models, there appears to be less understanding as to the influence of interrupted start-stop technology on the friction and wear behaviour of Al-Si surfaces used as cylinder liner materials.

It is well known that the reciprocating action of the piston stroke produces a range of lubrication regimes in the contact, from boundary at the stroke ends where velocity reversal inhibits formation of an elastohydrodynamic film, to mixed and EHL in the mid-stroke region [12-15]. It would be anticipated that regular start-stop occurrences would be disruptive to the EHL film formation in the mid-stroke region and potentially lead to a greater degree of asperity contact and possibly higher frictional energy loss and wear damage of the surfaces.

In order to investigate this hypothesis, an interrupted velocity start-stop laboratory test programme was devised around the European Urban Cycle standard $[5,16]$ and conducted under horizontal lubricated sliding conditions on a hyper-eutectic Al-Si alloy. Periods when the vehicle was stationary and in motion were calculated and averaged to produce a regular time dependent velocity interruption. Actual engine velocities are difficult to replicate on a laboratory scale tribometer as discussed by other authors [17, 18] and thus a test frequency was chosen which represented a matched idle engine frequency, described in detail elsewhere [16]. Further challenges to simulating conditions experienced in operational engines include lubricant starvation in a vertically sliding contact (and the associated local temperature rise), the influence of lubricant contamination (including soot and fuel) as well as the influence of different ring materials. However in order to assess the influence of velocity interruptions, simplified test conditions, including the use of a traditional cast iron piston ring [19] and a fresh supply of specification lubricant were selected for this study. The study focused on differences in friction and wear behaviour compared to an uninterrupted test and explained differences in surface tribo-film formation using a focused ion beam secondary ion mass spectrometry (FIB-SIMS) technique as a result of velocity interruptions. The results 
are summarised in terms of the potential implications of start-stop technology on the friction and wear behaviour of Al-Si alloys for cylinder liner applications.

\section{Experimental}

\subsection{Test Materials}

A commercially cast hyper-eutectic (A390 equivalent - Table 1) Al-Si cylinder liner (KolbenSchmidt Germany) was bored and mechanically honed according to the manufacturers specification (using plastic bonded diamond honing stones) to an inner diameter of $85 \mathrm{~mm}$. The final step in this process was a lapping treatment designed to preferentially remove the softer aluminium matrix and expose the harder silicon particles as the tribological contact surface. The honed surface was then protected by polyester tape prior to sectioning to produce conformal liner test samples $40 \times 27 \mathrm{~mm}$, Figure 1 . An area of the honed surface was imaged in 3D with an Alicona Infinite Focus focal plane variation light microscope in order to determine the condition of the Alusil surface prior to testing. Surface roughness values determined from the reconstructed surface using a $4 \mathrm{~mm}$ line profile with a Lc cut-off wavelength filter of $0.8 \mathrm{~mm}$.

The conformal counter-surface for the test was an un-sprung refined cast iron piston ring, also obtained from KolbenSchmidt. This was sectioned to a $26 \mathrm{~mm}$ circumferential length near the ring gap where deformation due to the ring being un-sprung would be considered to be minimal. Vickers hardness measurements of both the cast iron ring and Alusil cylinder liner material were taken on polished sections using a diamond Vickers hardness tester at a load of 10kgf for 10 seconds, with ten indents being made on each surface.

\subsection{Tribological Testing}

In order to simulate a reciprocating ring-liner contact from an internal combustion engine, a Phoenix Tribology TE77 High Frequency Reciprocating test machine was used. The conformal Alusil test liners were screwed to a lubricant bath and fixed to a heated test stage. In order to ensure test repeatability when samples were removed and replaced for gravimetric analysis, a parallel-sided metallic bar $(5 \times 30 \mathrm{~mm})$ was located along the length of the Alusil liner specimen and clamped prior to the test. This was then used as a subsequent reference point to carefully align the Alusil liner after test intervals. In order to correctly locate the cast iron piston ring in a conformal geometry and avoid edge wear, a small amount of lubricant was first applied to the test surface. The piston ring segment was then placed upon the Alusil liner in a conformal geometry, as shown in Figure 1, and the ring clamp arm of the TE77 moved into position either side of the ring. The clamp was gently tightened to preserve the conformal contact of both surfaces. The area of contact was examined by assessing the footprint left by a thin film of lubricant on the ring when brought into contact with a dry Alusil surface, and the ring repositioned if necessary. A fully synthetic commercial specification lubricant for this material couple (Castrol EDGE 5W-30) was drip fed 
onto the test surface via a feed hose attached to the loading head at a rate of $6 \mathrm{ml} / \mathrm{min}$. Prior to sliding, the test surfaces were heated to a temperature of $100^{\circ} \mathrm{C}$ and allowed to stabilise for 30 minutes. Each test was then subject to a conditioning phase according to ASTM: G171 in order to run each of the contacting surfaces in. This involved application of a minimum load of $5 \mathrm{~N}$ followed by acceleration to the test frequency of $23 \mathrm{~Hz}$ at a stroke length of $25 \mathrm{~mm}$. The load was then incrementally raised at 60 second intervals by $5 \mathrm{~N}$ up to the maximum test load of $150 \mathrm{~N}$, whereupon the load was incrementally stepped down in the same manner to $5 \mathrm{~N}$.

\subsection{Start-Stop Velocity Testing}

Once the conditioning phase had been completed, the test load was increased to $150 \mathrm{~N}$ and a cycling interrupted start-stop velocity programme commenced. This consisted of intervals of sliding at $23 \mathrm{~Hz}$ for 60 seconds interrupted by periods of no motion for 35 seconds after which sliding commenced again for 60 seconds and the cycle repeated, Figure 2 a). This simulated average periods of vehicle motion and arrest derived from the European Urban Cycle but also included an addition time increment (15s) in order to compensate for the acceleration lag of the laboratory test tribometer, which was less than a fired engine. The static and dynamic friction coefficients were continuously monitored throughout the test by means of a lateral piezo-electric force transducer attached to the sample stage. Tests were stopped at three test intervals of 87, 225 and 495 minutes, Figure 2b), with samples cooled to room temperature, cleaned with petroleum ether and weighed using a Mettler Toledo precision balance with an accuracy of $\pm 5 \times 10^{-}$ ${ }^{6} \mathrm{~g}$ in order to determine mass loss. The cast iron piston rings were not weighed until the end of the third test interval in order not to disturb the specimen conformality. The Alusil samples were replaced in exactly the same position as outlined above and again heated to $100^{\circ} \mathrm{C}$ for 30 minutes prior to sliding again.

In order to generate a comparison between the start-stop velocity and an uninterrupted test sample, the latter was tested under the same conditions (run in, load and temperature) at $23 \mathrm{~Hz}$ but without velocity interruption for the same test length intervals. A total of five tests were conducted; the first to determine satisfactory running-in conditions were achieved from the conditioning phase and then two repeats of the first test segment for the interrupted and uninterrupted test to validate similar friction behaviour.

\subsection{Surface Tribo-film Analysis}

A Zeiss NVision 40 dual beam SEM-FIB combined with a Hiden Analytical EQS quadrupole secondary ion mass spectrometer (SIMS) was used to identify the presence of surface tribo-films present on the start-stop velocity and continuously run test surfaces. Surfaces were first cleaned in petroleum ether in order to remove excess lubricant. Areas from the mid-stroke position of both test liners were then carefully sectioned using a low-speed diamond saw in order to minimise heating and preserve the worn 
surface. Samples were mounted on aluminium stubs using epoxy resin and painted with silver conduction paint between the stub and base of the liner in order to ensure good a good conduction pathway. The focused ion beam uses a liquid metal gallium source to sputter ions from the surface of the test specimens. In order to tune the Hiden Analytical EQS quadrapole detector, an area of $30 \times 30 \mu \mathrm{m}$ near the region of interest was sputtered at a beam energy of $5 \mathrm{kV}, 3 \mathrm{nA}$ and the detector tuned to the aluminium $27 \mathrm{amu}$ signal. The same beam current was then used to scan selected areas of the worn surface and chemical maps of Al, Si, Zn, Mo and Fe were generated using Hiden ESM mapping software and a $200 \times 200$ pixel area.

Further analysis was performed using dynamic SIMS on the Al matrix and a Si particle from both surfaces of an uninterrupted and a start-stop test. Elemental depth profiling was conducted by sputtering material from a $20 \times 20 \mu \mathrm{m}$ box at $5 \mathrm{kV}$, 3nA beam current and by using the quadrupole detector to detect the atomic mass units signal from the same elements as above, as a function of time. In order to accurately convert sputter time to depth, SEM stereo-microscopy was performed on each FIB sputtered crater. Three eucentric tilted secondary electron images were taken of each crater at $5^{\circ}, 0^{\circ}$ and $-5^{\circ}$ stage tilt angles. The images were reconstructed in 3D using Mex software (Alicona, Austria) and a linear cross section profile used to measure the depth of the FIB sputtered crater compared to nearby un-sputtered material. Assuming a linear sputter rate for all species, the time dependent dynamic SIMS profiles could be converted to accurate depth profiles and tribo-film thicknesses subsequently calculated and compared between samples. Error bounds were calculated based on the surface roughness of the un-sputtered and sputtered crater surface.

\section{Results}

3.1 Surface Properties

Optical microscopy of the honed surface, Figure 3 a) showed how the surfaces of equiaxed primary silicon phases were exposed within the aluminium matrix. The honing lay direction was clearly visible from both the optical image and the surface depth map, Figure $3 \mathrm{~b}$ ) which also indicated that the larger primary silicon particles were raised above the aluminium matrix to a maximum height of round $1.5 \mu \mathrm{m}$. The surface roughness $(\mathrm{Ra})$ from this area of the sample was measured to be $0.29 \pm 0.02 \mu \mathrm{m}$, which was marginally above engine bore surface finish specification for Alusil $(0.21 \mu \mathrm{m} \mathrm{Ra})$. The relative Vickers hardness $\left(\mathrm{H}_{\mathrm{V}}\right)$ of the Alusil liner and refined cast iron piston ring were $138 \pm 3$ and $296 \pm 14$ respectively, although for the Alusil liner the hardness was a contribution from both the harder silicon phase as well as the softer aluminium.

3.2 Friction Behaviour

Figure 4 a) is a plot of the conditioning phase (from the start-stop velocity test) when the surfaces were run in together. It was observed that the dynamic coefficient of friction was particularly sensitive during low loading $(5-30 \mathrm{~N})$ where a relatively high coefficient of friction was observed, up to 0.8 . However as 
the conditioning load was increased from $30 \mathrm{~N}$ up to the test load of $150 \mathrm{~N}$, the coefficient of friction decreased to around 0.1 and was relatively stable across this load range.

Static friction coefficients observed when sliding took place after each testing interval where similar in value to that observed during the conditioning phase, 0.8-0.9, and were consistent between both uninterrupted and start-stop tests. Once the normal load had attained the maximum test load of $150 \mathrm{~N}$, dynamic friction coefficients were again similar to that observed during the conditioning test phase, for all test conducted.

The effect of the start-stop velocity interruptions on the dynamic friction coefficient is displayed in Figure $4 \mathrm{~b})-\mathrm{d}$ ), which show values for each of the three sequential test steps in respective order. It was seen that each start-stop velocity interval resulted in a static friction coefficient spike when sliding recommenced. The maximum value these peaks attained was around 0.15 notably lower than the initial static friction coefficient of $0.8-0.9$, but consistent for all test intervals.

For the periods of sliding during the start-stop test, a constant value for the dynamic friction coefficient was established once the test frequency had attained $23 \mathrm{~Hz}$. This was around 0.09 and again consistent across the three test intervals. Comparatively, the dynamic friction coefficient of the uninterrupted run test was very similar at 0.1 , slightly above the start-stop test until the third test segment, when values were identical at 0.09 .

3.3 Surface Contact Potential

Figure $4 \mathrm{~b}$ )-d) gives an indication of the measured electrical contact potential between the cast iron ring and Alusil liner. During the conditioning run in phase, it was observed that formation of an insulating tribo-layer occurred relatively quickly, Figure 4 a), which was sensitive to changes in the test load. This was noted in Figure 4 b) immediately after the conditioning phase, when the increase of the test load to $150 \mathrm{~N}$ resulted in the contact potential being significantly reduced from 47 to $7 \mathrm{mV}$ or $1 \mathrm{mV}$ for the uninterrupted and interrupted start-stop tests respectively, after about 59 minutes. For the second and third test segments, Figure 4 c) \& d), this initial drop was observed to be notably less (Second segment $48 \mathrm{mV}$ to 26 and $20 \mathrm{mV}$; third segment $-48 \mathrm{mV}$ to 34 and $22 \mathrm{mV}$, respectively). For the uninterrupted test it was observed that as the test progressed, the contact potential steadily increased, plateauing after approximately 75 minutes. The start-stop test also exhibited a steady increase in electrical contact resistance when sliding, similarly plateauing after approximately 75 minutes, however there were some notable differences. The most obvious was that when the test velocity was interrupted, the contact potential fell to zero. The second observation was that when sliding recommenced, the contact potential increased again, usually to a higher level than that observed just prior to the velocity interruption. This was followed by a steady decrease in the value until the next velocity transient caused the value to drop to zero again. This effect was consistent across all tests. At longer sliding times, a small increase in the maximum contact potential compared to values attained after 75 minutes was noted, however of more 
significance was the fact that the contact potential for the uninterrupted test was always above that of the start-stop tests by approximately $5 \mathrm{mV}$.

3.4 Specific Wear Rates

The relative changes in mass loss for the Alusil liner segments measured gravimetrically at each test interval are presented in Figure 5. It can be seen that whilst the initial mass loss was similar for both tests, as the sliding distance increased, the mass loss for the uninterrupted test increased relative to the startstop test between 2 and $8 \mathrm{~km}$. After $8 \mathrm{~km}$ sliding distance, the uninterrupted test assumed a similar mass loss gradient to the start-stop test, although overall values were still notably higher than the start-stop liner. The influence of the velocity interruptions on the total sliding distance was immediately apparent, as both tests were run for the same time intervals. Specific wear rates, calculated from the mass loss data presented in Figure 5 are summarised in Table 2 and have also been converted to material removal rates in $\mathrm{nm} / \mathrm{h}$ based on the stroke length of the wear scar $(25 \mathrm{~mm})$ and the contact radius of the piston ring (26mm).

Table 3 shows the mass loss for the refined cast iron piston rings for both uninterrupted and start-stop tests, measured after the conclusion of all tests. It was observed that the overall mass loss for both counter-surfaces was similar. However, when taking into account the extended distance for which the uninterrupted test was run (due to a lack of velocity interruption) it was apparent that the mass loss rate was significantly higher for the piston ring tested with start-stop velocity interruptions.

\subsection{FIB-SIMS Mapping}

Figure 6 a) is a secondary electron image from the surface of the start-start test surface after sliding for $11.14 \mathrm{~km}$. The image, taken at the mid-stroke position of the test sample shows two silicon particles raised above the aluminium matrix. The surface of the silicon particles exhibited lateral marks consistent with abrasive contact in the sliding direction, which was horizontal in this instance. The surrounding aluminium matrix exhibited significant deformation such that the original honing marks could not be observed.

FIB-SIMS mapping of aluminium, silicon, iron, zinc and molybdenum atomic masses for the same area are shown in Figure $6 \mathrm{~b}$ )-f). The aluminium signal was the strongest observed signal and provided clear evidence of the position of the silicon particles by the lack of observed intensity at these positions. The silicon map, Figure $6 \mathrm{c}$ ), by contrast was not the inverse of the aluminium map, but rather showed a more diffuse signal across the entire sampled area, as would be expected from a hyper-eutectic composition. The signal for silicon appeared strongest at the edge of the silicon particles, where higher magnification revealed the absence of any apparent tribo-films. The iron map confirmed the presence of iron on the Alusil surface, notably concentrated on either the surface of the Si particles or else as what appears to be a transferred particle, observed on the upper right of Figure 6 a) and d). The maps of zinc and 
molybdenum, Figure 6 e) and f) respectively, showed how each species was preferentially observed on either the silicon particles or the surrounding matrix, respectively.

3.6 FIB-SIMS Depth Profiling

Individual areas of both the uninterrupted and start-stop test surfaces around the mid-stroke position are shown in Figure 7 a)-d), where FIB-SIMS depth profiles have been conducted. Figure 7 a) and b) show the areas of matrix and a Si particle from the uninterrupted test respectively, whilst Figure $7 \mathrm{c}$ ) shows the start-stop matrix and Si particle together. Figure $7 \mathrm{~d}$ ) is a higher magnification image of the corner from the depth profile crater made on the start-stop Si particle and showed the presence of a surface tribo-film which has in part been sputtered away during the depth profile measurement.

The corresponding depth profiles for the same areas in Figure 7 are shown in Figure 8. It was clear that for both profiles on the matrix that aluminium was the strongest observed signal $\left(10^{5} \mathrm{c} / \mathrm{s}\right)$, with comparable levels of silicon also found on both test surfaces. The presence of iron was also noted $\left(10^{4}\right.$ $\mathrm{c} / \mathrm{s}$ ) at the surface, decaying after $1 \mu \mathrm{m}$ depth to $10^{3} \mathrm{c} / \mathrm{s}$ for the uninterrupted test and $\approx 10^{2} \mathrm{c} / \mathrm{s}$ for the startstop surface. A constant signal for molybdenum was present through the entire depth profile of both uninterrupted and start-stop matrix test surfaces, again marginally higher for the former. Whilst the zinc map in Figure 6 indicated $\mathrm{Zn}$ to be predominantly associated with the location of the Si particles, closer inspection revealed signal also from the matrix, confirmed by the depth profiles of Figure 8 a) and c) where a discreet zinc rich layer was observed. This layer was thicker on the uninterrupted sample $(295 \mathrm{~nm})$ compared to the start-stop matrix surface (143nm), Table 4.

Figure $8 \mathrm{~b}$ ) and d) indicated that a zinc rich film was present on the silicon particles, again thicker on the uninterrupted sample $(436 \mathrm{~nm})$ compared to the start-stop surface $(184 \mathrm{~nm})$. The molybdenum signal, in contrast to the matrix profile, was only present to a depth of $385 \mathrm{~nm}$ and $108 \mathrm{~nm}$ on the surface of silicon particles from the uninterrupted and start-stop surfaces, respectively.

In order to calculate the above tribo-film thicknesses it was necessary to measure the depth of each FIB sputtered crater using SEM stereo-microscopy and Mex software from Alicona. Figure 9 a) is a colour depth map generated from a topographical reconstruction of the FIB-SIMS depth profile crater on the Si particle examined on the uninterrupted test surface. A linear profile is taken across the crater depth, shown in Figure 9 b). Assuming a linear sputter rate, depth profiles were calculated accordingly, however as the top and bottom boundaries of the crater can be difficult to define, an error analysis was performed on the areas between the red lines. Mean values were calculated within one standard deviation and error propagation was calculated to be within $10 \%$ of the values stated in Table 4 .

\section{Discussion}


Despite the higher bulk hardness of the refined cast iron piston ring $\left(296 \mathrm{H}_{\mathrm{V}}\right.$ ) compared to the bulk hardness of the Alusil surface $\left(138 \mathrm{H}_{\mathrm{V}}\right)$, the relative mass loss of the refined cast iron piston rings was, in the case of the start-stop tests, an order of magnitude higher than that measured from the corresponding Alusil liner after the third test interval. The reason for this was wear of the cast iron ring by the locally harder Si particles which were both angular at the particle edges (Figure 2) and stood proud of the contact surface (Figure 6) as a result of the honing operation. FIB-SIMS mapping showed how transfer of iron from the counter-surface occurred, with an iron rich particle observed near a raised primary silicon particle in Figure 6 a) and d). Such behaviour is typical of lubricated sliding of aluminium based metal matrix composites where the reinforcement phase is harder than the sliding counter-surface and abrades the latter by a two-body action [20]. The fact that the relative mass loss rate for the cast iron ring subject to interrupted start-stop velocities was significantly higher $\left(3.14 \times 10^{-7} \mathrm{~g} / \mathrm{m}\right)$ than the test performed uninterrupted $\left(1.88 \times 10^{-7} \mathrm{~g} / \mathrm{m}\right)$ suggested that velocity interruption caused an increase in the level of abrasion of the piston ring by the prominent Si particles in the Alusil liner. This enhanced level of wear of the piston ring may have been responsible for more effectively running-in the surface of the start-stop test, beyond the initial conditioning phase, such that a linear mass loss gradient as a function of sliding distance was quickly established. In contrast the uninterrupted test required a greater sliding distance (up to $8 \mathrm{~km}$ ) in order to achieve a similar mass loss rate and could be why a higher specific wear rate was observed. Thus interrupted velocities could be an effective way to achieve conformal run-in surfaces in piston assemblies, although piston ring pack lifetimes would have to be investigated further. Lubricated sliding investigations of ring - liner contacts often result in difficulty detecting wear rates due to the very low rate of material removal. The specific wear rates observed in the present study were of the order $1 \mathrm{x}$ $10^{-7} \mathrm{~mm}^{3} / \mathrm{Nm}$, which was comparable with tests performed by Li etal [21] using a Rutherford Backscatter Detector technique to trace wear as a function of an implanted Au layer on a steel liner material. Other methods of measuring engine bore wear such as radio-active nuclide tracer (RNT) techniques [22, 23] or measurement of subtle changes in height associated with aluminium or silicon particle wear using interferometry [8, 9, 24-27] often refer to the regime of Ultra Mild Wear (UMW) and quote surface losses in $\mathrm{nm} / \mathrm{h}$ or $\mathrm{nm} / \mathrm{m}$. Table 2 showed how the rate of material removal decreased with test length and was estimated to be $35 \mathrm{~nm} / \mathrm{h}$ at the end of the start-stop test compared with $68 \mathrm{~nm} / \mathrm{h}$ for the uninterrupted test. These values were slightly higher than that reported by Dienwiebel for RNT measurements on Al-Si cylinder bore wear [8], however as a constant rate of material loss had not been attained in the present study, it could be concluded that the present tests were operating in the same Ultra Mild Wear regime.

4.2 Friction Behaviour

Dynamic friction coefficients of all tests were in the range 0.08-0.1 and therefore in agreement with published literature on lubricated sliding of hyper-eutectic Al-Si against ferrous counter-surfaces [28-31]. 
The slightly higher dynamic friction coefficient during the first and second test segments for the uninterrupted test, compared to start-stop, could be linked to the simultaneously higher wear rate of the Al-Si liner and was thought to relate to the longer sliding time required to achieve a polished conformal surface with the piston ring. This was evident only in the third segment of the uninterrupted test when dynamic friction values and mass loss gradients were similar to start-stop tests.

The fact that dynamic friction coefficients for both test types were similar indicated that start-stop did not impact on the fluid film lubrication behaviour of the contact. Indeed, FIB-SIMS mapping and depth profiling clearly demonstrated how lubricant boundary additives, such as Molybdenum based friction modifiers, had been activated on both the aluminium matrix and Si particle surfaces. Such additives were responsible for lowering the static friction coefficient during interrupted test re-starts to 0.15 compared to 0.8-0.9 after test intervals. This reversible behaviour (where cleaning of the tribological surface during test intervals resulted in higher static friction upon test re-start) was also observed by Timmermans and Froyen during lubricated pin on disc tests with similar hyper-eutectic Al-Si combinations [28]. The explanation is that formation of Mo-based friction modifiers required a localised energy input, such as that from an asperity contact, in order for a tribo-chemical reaction to occur [19, 32]. If sliding was uninterrupted then sufficient low shear strength films could form allowing low static friction coefficients under boundary lubrication. For start-stop tests conducted in the present study, it appeared from the FIBSIMS depth profiling results, that there was little change in Mo-based low friction tribo-film thickness on the aluminium matrix (Figure 8) compared to the uninterrupted tests. The presence of Mo was also observed on the load bearing Si particles and whilst the thickness of this layer was notably less for the start-stop tests, it appeared that even the presence of a very think Mo layer could provide similar dynamic friction coefficients compared to the uninterrupted test.

\subsection{Surface Tribo-layer}

On-line contact potential measurements measured during testing contributed further information about formation of surface tribo-films. It was clear from Figure 4 a) that load influenced the formation of surface insulating tribo-layers as contact potentials dropped with an increase in conditioning and test load. When the test load was reduced the surface tribo-film re-formed, increasing the contact potential between the surfaces and illustrating the sensitivity of surface tribo-film formation to contact conditions.

The contact potential was also sensitive to start-stop velocity interruptions. It was interesting that during all velocity interruptions the contact potential fell to zero, indicating metallic contact between the piston ring and Alusil liner. This was further evidence of boundary additive function reducing the static re-start friction coefficient to 0.15 . When re-starting, contact potential readings exhibited a peak associated with the static friction peak, again confirming tribo-chemical reaction associated with frictional energy input 
from local flash temperatures and also consistent with other studies on anti-wear pad formation [19, 31, 33, 34].

It was clear when comparing contact potential between the start-stop and uninterrupted tests that values were higher for the latter indicating a thicker tribo-film, which was consistent with Zn-based anti-wear pad thickness measured by FIB-SIMS. Over the total test length, contact potential values steadily increased with test time, again consistent with the theory that anti-wear film formation and growth required sliding to occur [29, 33-36].

Depth profiling showed that whilst lubricant additive function was not inhibited for start-stop tests, antiwear pad formation on silicon and aluminium contact surfaces was not as effective compared to uninterrupted tests. This was a direct result of the metallic contact resulting from the velocity interruption and the subsequent re-starting of sliding. The FIB-SIMS mapping clearly showed regions of preferential $\mathrm{Zn}$ and Mo rich layers dissociated on silicon and matrix respectively, although as shown from the depth profiles in Figure 8 this was not exclusively the case, with small amounts of Mo on $\mathrm{Si}$ and $\mathrm{Zn}$ in the matrix. This was broadly consistent with work by Nicholls et al [34, 36, 37] who used a number of X-Ray techniques (XANES, X-PEEM) to determine the mechanism of preferential long chain poly-phosphate anti-wear pad formation from ZDDP additives at contacting Si interfaces. The presence of iron was also noted on the contact surface of the Si particles, Figure $5 \mathrm{~d}$ ), and would be consistent with the theory that a ferrous oxide surface is necessary to allow desorption of $\mathrm{Zn}$ based additives prior to formation of a glassy phosphate anti-wear pad $[19,31,34,36,38]$. The presence of Al also on the surface of the Si particles, Figure $8 \mathrm{~b}$ ) suggested that the anti-wear pad formation on Si particles resulted from the wear, transfer and mixing of debris caused during the initial running-in period of sliding, which would be in agreement with more recent theories of how Al-Si surfaces evolve as a result of lubricated sliding wear [8]. This would also explain the presence of a small amount of Mo present on the Si particle surface, although it was clear from the FIB-SIMS mapping that the majority of the Mo signal was found in the Al matrix. Similar studies on hyper-eutectic Al-Si alloys using Mo-based additives [31, 36] have found $\mathrm{MoS}_{2}$ formation to be independent of substrate composition and thus the present work suggests that the difference in Mo signal observed between matrix and Si particles is more influenced by sliding contact then chemical desorption. Si particles are considered the load bearing element of the liner surface, but the presence of even 100nm of Mo-based friction modifier, Figure $8 \mathrm{~d}$ ), was sufficient to reduce the static friction coefficient during the start-stop cycles, Figure 4.

Placing the current work in a wider context, it was clear that whilst friction behaviour was not significantly inhibited, start-stop interrupted velocities had a detrimental effect on the thickness of antiwear film formation on Al-Si cylinder liner materials. This could have lifecycle implications for wear when using these materials in hybrid or start-stop engine applications. The frequency of test interruptions 
may play a factor in the time required for an effective tribo-film to be generated, competing with tribofilm removal as a result of velocity interruption and is clearly an area that warrants further investigation.

\section{Conclusions}

Summarising the main findings of this work we can conclude the following:

- A preliminary start-stop test programme for hyper-eutectic Al-Si alloys developed based around the European Urban Cycle to simulate lubricated sliding of the piston ring/cylinder liner interface using a laboratory based tribometer.

- It was shown that start-stop sliding against a hyper-eutectic Al-Si cylinder liner caused more wear to the cast iron piston ring compared to an uninterrupted test.

- Quicker running in of the cast iron piston ring as a result of start-stop sliding reduced wear rates of the Al-Si surface as contact loads were more evenly distributed.

- Start-stop sliding did not significantly affect dynamic friction coefficients or friction modifier activation.

- Transfer of ferrous material from the counter-surface was associated with concurrent formation of Zn-based anti-wear pads on protruding Si particles, consistent with other reports in the literature.

- Contact potential and FIB-SIMS depth profiling indicated an increase in boundary lubrication contact at the mid-stroke region of the Al-Si cylinder surface resulting in a decrease in Zn-based anti-wear pad thickness.

- These findings may have implications for the use of hyper-eutectic Al-Si cylinder liner in startstop engine cycles, although further work is required to establish the long term effects over vehicle lifetimes.

\section{Acknowledgements}

The authors would like to acknowledge access to the Southampton Nanofabrication Centre (SNC) for use of the Zeiss NVision 40 dual beam FIB-SEM. 


\section{References}

[1] J. Dargay, D. Gately, M. Sommer, Vehicle ownership and income growth, Worldwide: 1960-2030, Energy Journal, 28 (2007) 143.

[2] J. King, The King review of low-carbon cars: The potential for CO2 Reduction, HM Stationery Office, 2007.

[3] N. Fonseca, J. Casanova, M. Valdés, Influence of the stop/start system on CO2 emissions of a diesel vehicle in urban traffic, Transportation Research Part D: Transport and Environment, 16 (2011) 194-200. [4] IAI, Improving sustainability in the transport sector through weight reduction and the application of aluminium-model, 2008

[5] Member Council Directive, 70/220/EEC, With revisions to 2007, European Union, 1970

[6] G. Ryk, Y. Kligerman, I. Etsion, Experimental investigation of laser surface texturing for reciprocating automotive components, Tribology Transactions, 45 (2002) 444-449.

[7] Y. Kagohara, S. Takayanagi, S. Haneda, M. Fujita, Y. Iwai, Tribological property of plain bearing with low frictional layer, Tribology International, 42 (2009) 1800-1806.

[8] M. Dienwiebel, K. Pöhlmann, M. Scherge, Origins of the wear resistance of AlSi cylinder bore surfaces studies by surface analytical tools, Tribology International, 40 (2007) 1597-1602.

[9] B. Slattery, T. Perry, A. Edrisy, Microstructural evolution of a eutectic Al-Si engine subjected to severe running conditions, Materials Science and Engineering: A, 512 (2009) 76-81.

[10] F. Davis, T. Eyre, The effect of silicon content and morphology on the wear of aluminium-silicon alloys under dry and lubricated sliding conditions, Tribology International, 27 (1994) 171-181.

[11] E. Köhler, J. Niehues, Aluminum-matrix composite materials in combustion engines, in: K.U. Kainer (Ed.) Metal Matrix Composites, Wiley-VCH, 2006, pp. 95-109.

[12] R. Taylor, Transient effects in engines operating at steady speeds \& loads, Tribology and Interface Engineering Series, 43 (2003) 123-131.

[13] B.J. Hamrock, S.R. Schmid, B.O. Jacobson, Fundamentals of fluid film lubrication, CRC press, 2004.

[14] D. Dowson, G.R. Higginson, Elasto-hydrodynamic lubrication, Pergamon Press, 1977.

[15] C.F. Taylor, The internal-combustion engine in theory and practice: Thermodynamics, fluid flow, performance, M.I.T. Press, 1985.

[16] J.C. Walker, T.J. Kamps, R.J.K. Wood, Assessment of 3D surface texture evolution of a hypereutectic Al-Si liner subject to transient velocities, in: W.J. Bartz (Ed.) Proceedings 18th International Colloguium on Tribology, TAE Esslingen, 2012.

[17] P.M. Lee, R.J. Chittenden, Consideration of test parameters in reciprocating tribometers used to replicate ring-on-liner contact, Tribology Letters, 39 (2010) 81-89. 
[18] S.E. Hartfield-Wünsch, S.C. Tung, C.J. Rivard, Development of a Bench Wear Test for the Evaluation of Engine Cyliner Components and the Correlation with Engine Test Results, Society of Automotive Engineers, 1993.

[19] A. Neville, A. Morina, T. Haque, M. Voong, Compatibility between tribological surfaces and lubricant additives - How friction and wear reduction can be controlled by surface/lube synergies, Tribology International, 40 (2007) 1680-1695.

[20] J.C. Walker, W.M. Rainforth, H. Jones, Lubricated sliding wear of behaviour of alumninium alloy composites, Wear, 259 (2005) 577-589.

[21] Y.R. Li, D. Shakhvorostov, G. Pereira, A. Lachenwitzer, W. Lennard, P. Norton, A Novel Method for Quantitative Determination of Ultra-low Wear Rates of Materials, Part I: On Steels, Tribology Letters, 33 (2009) 143-152.

[22] M. Scherge, K. Pöhlmann, A. Gervé, Wear measurement using radionuclide-technique (RNT), Wear, 254 (2003) 801-817.

[23] E.W. Schneider, D.H. Blossfeld, Radiotracer method for measuring real-time piston-ring and cylinder-bore wear in spark-ignition engines, Nuclear Instruments and Methods in Physics Research Section A: Accelerators, Spectrometers, Detectors and Associated Equipment, 505 (2003) 559-563.

[24] M. Chen, A. Alpas, Ultra-mild wear of a hypereutectic Al-18.5 wt.\% Si alloy, Wear, 265 (2008) 186195.

[25] M. Chen, T. Perry, A. Alpas, Ultra-mild wear in eutectic Al-Si alloys, Wear, 263 (2007) 552-561.

[26] B. Slattery, A. Edrisy, T. Perry, Investigation of wear induced surface and subsurface deformation in a linerless Al-Si engine, Wear, 269 (2010) 298-309.

[27] S. Dey, T. Perry, A. Alpas, Micromechanisms of low load wear in an Al-18.5\% Si alloy, Wear, 267 (2009) 515-524.

[28] G. Timmermans, L. Froyen, Tribological performance of hypereutectic P/M Al-Si during sliding in oil, Wear, 231 (1999) 77-88.

[29] A.N.K. Jadoon, R.A. Mufti, Tribological behaviour of alternate hypereutectic Al-Si alloys with different antiwear additives, Tribology - Materials, Surfaces and Interfaces, 4 (2010) 61-73.

[30] S. Das, S.K. Biswas, Boundary lubricated tribology of an aluminium-silicon alloy sliding against steel, Tribology Letters, 17 (2004) 623-628.

[31] X. Xia, A. Morina, A. Neville, M. Priest, R. Roshan, C.P. Warrens, M.J. Payne, Tribological performance of an Al-Si alloy lubricated in the boundary regime with zinc dialkyldithiophosphate and molybdenum dithiocarbamate additives, Proceedings of the Institution of Mechanical Engineers Part JJournal of Engineering Tribology, 222 (2008) 305-314.

[32] R.F. Haycock, A.J. Caines, J.E. Hillier, Automotive lubricants reference book, John Wiley \& Sons Inc, 2005. 
[33] A.M. Barnes, K.D. Bartle, V.R.A. Thibon, A review of zinc dialkyldithiophosphates (ZDDPS): characterisation and role in the lubricating oil, Tribology International, 34 (2001) 389-395.

[34] M.A. Nicholls, T. Do, P.R. Norton, M. Kasrai, G.M. Bancroft, Review of the lubrication of metallic surfaces by zinc dialkyl-dithiophosphates, Tribology International, 38 (2005) 15-39.

[35] A. Morina, A. Neville, M. Priest, J. Green, ZDDP and MoDTC interactions and their effect on tribological performance-tribofilm characteristics and its evolution, Tribology Letters, 24 (2006) 243256.

[36] A. Jiménez, A. Morina, A. Neville, M. Bermúdez, Surface interactions and tribochemistry in boundary lubrication of hypereutectic aluminium-silicon alloys, Proceedings of the Institution of Mechanical Engineers, Part J: Journal of Engineering Tribology, 223 (2009) 593-601.

[37] M.A. Nicholls, P.R. Norton, G.M. Bancroft, M. Kasrai, G.D. Stasio, L.M. Wiese, Spatially resolved nanoscale chemical and mechanical characterization of ZDDP antiwear films on aluminum-silicon alloys under cylinder/bore wear conditions, Tribology Letters, 18 (2005) 261-278.

[38] G. Pereira, A. Lachenwitzer, M. Nicholls, M. Kasrai, P. Norton, G. Stasio, Chemical characterization and nanomechanical properties of antiwear films fabricated from ZDDP on a near hypereutectic Al-Si alloy, Tribology Letters, 18 (2005) 411-427. 
Figures

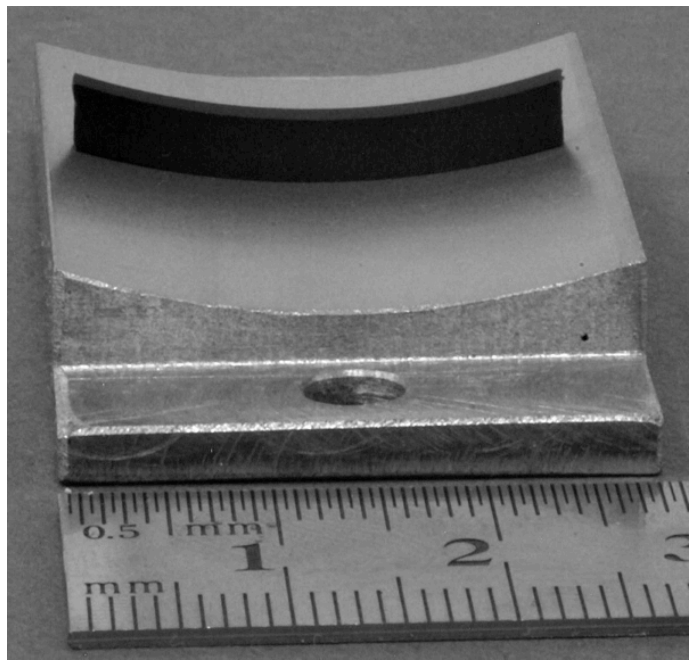

Figure 1. Sectioned Alusil liner and conformal refined cast iron piston ring samples.

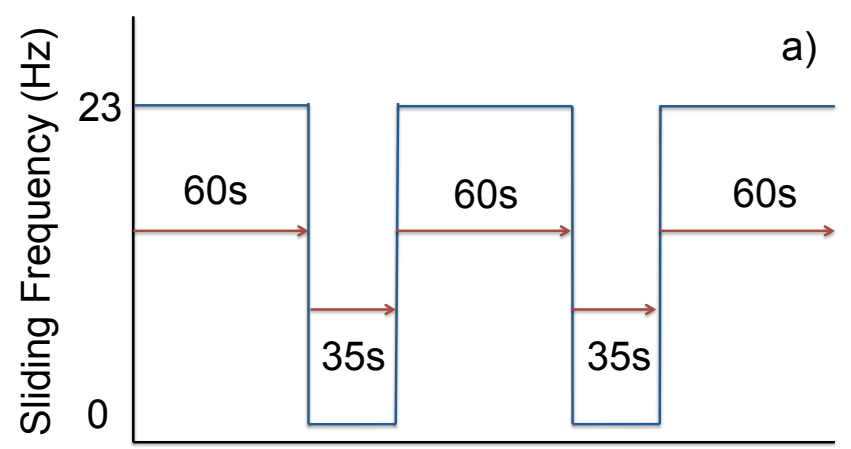

Sliding Time (s)

)

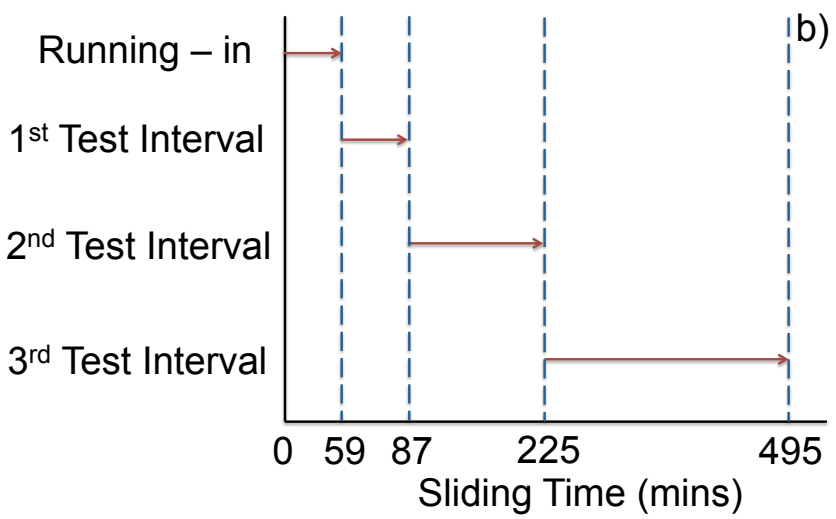

Sliding Time (mins)

Figure 2. Graphs to show a) Start-Stop sliding times and b) Test Schedule.

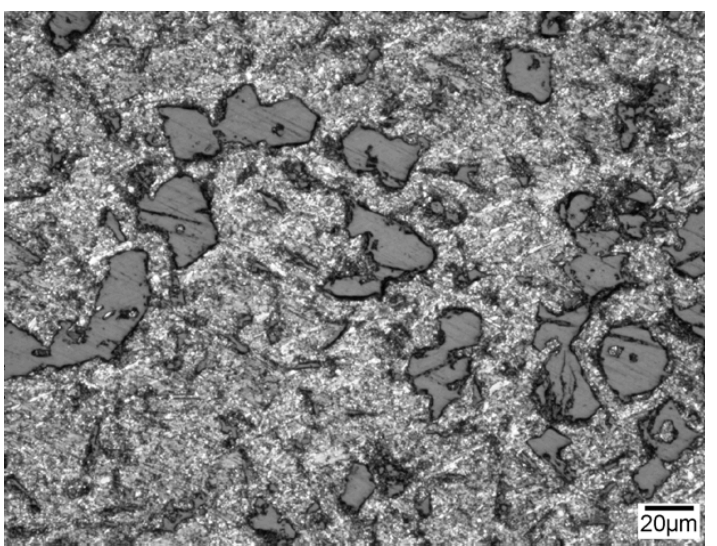

Figure 3. a) Optical micrograph of the Alusil liner and b) corresponding colour depth map from the same area. 

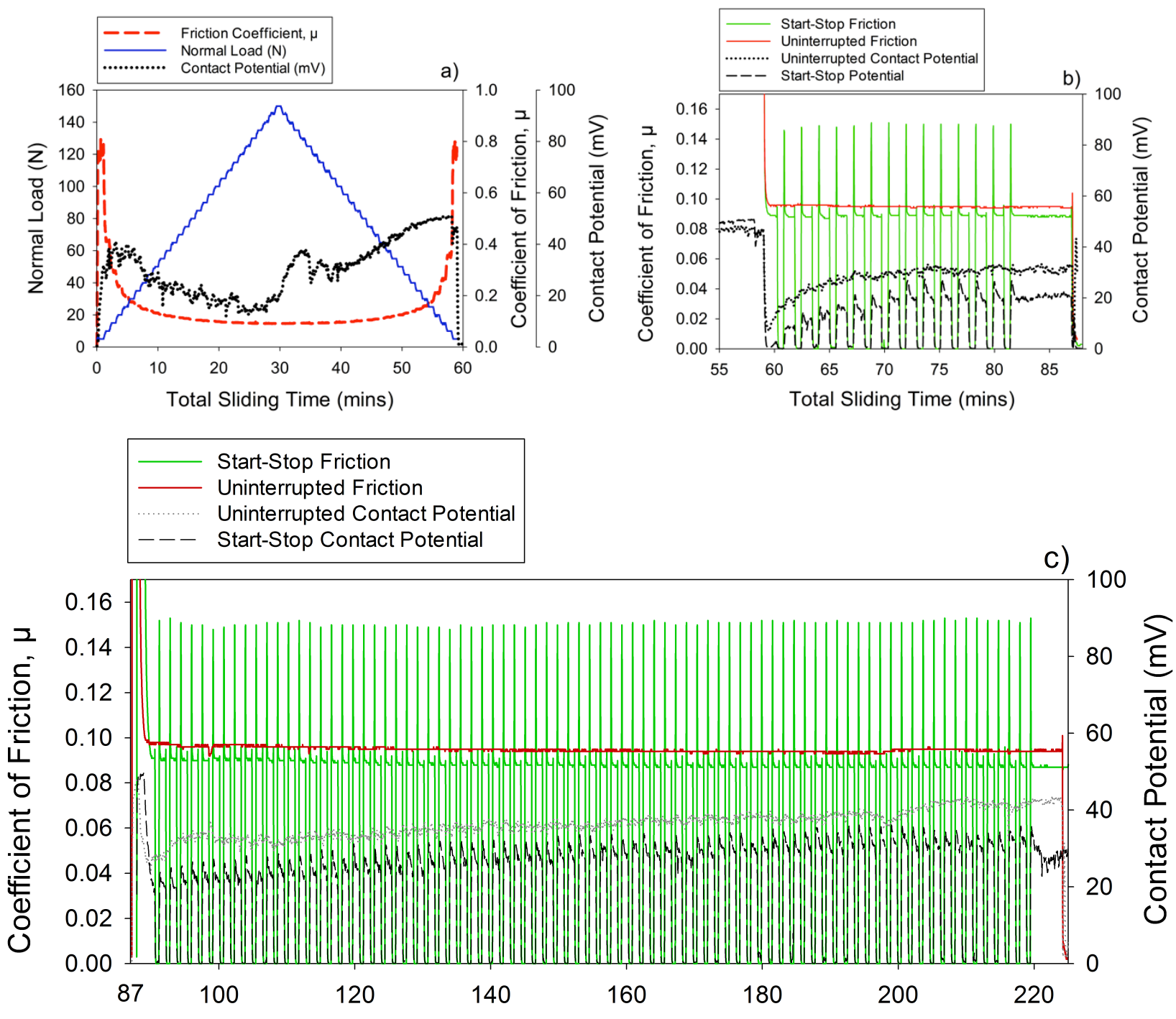

Total Sliding Time (mins)

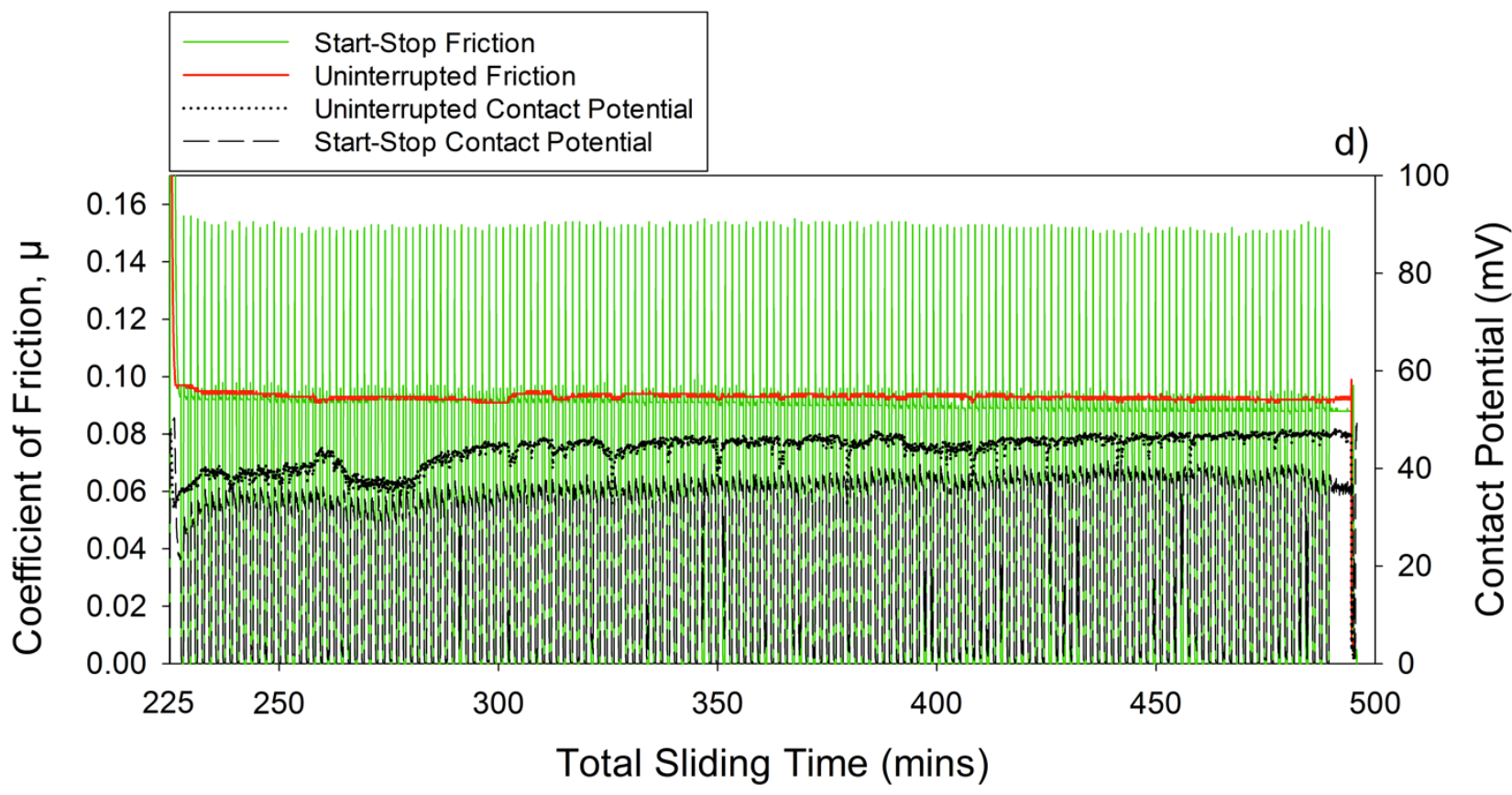

Figure 4. Dynamic friction coefficients and contact potentials of a) Conditioning sequence and test segments one (b), two (c) and three (d). 


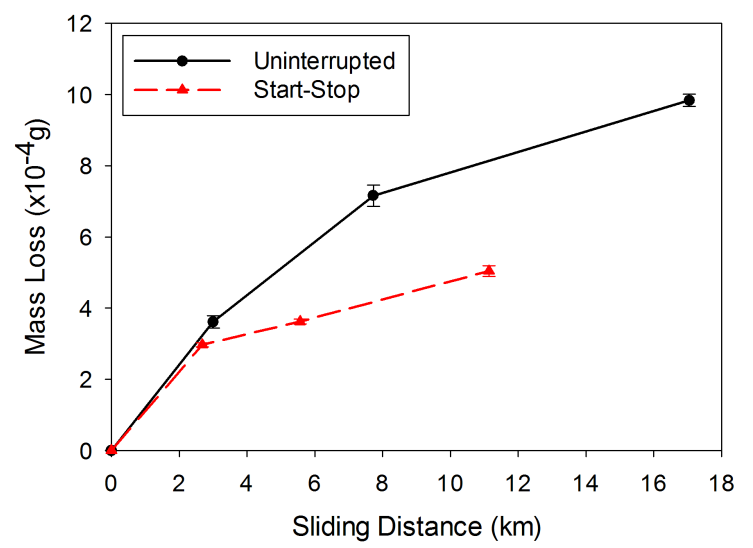

Figure 5. Mass loss vs sliding distance for un-interrupted and start-stop tests.
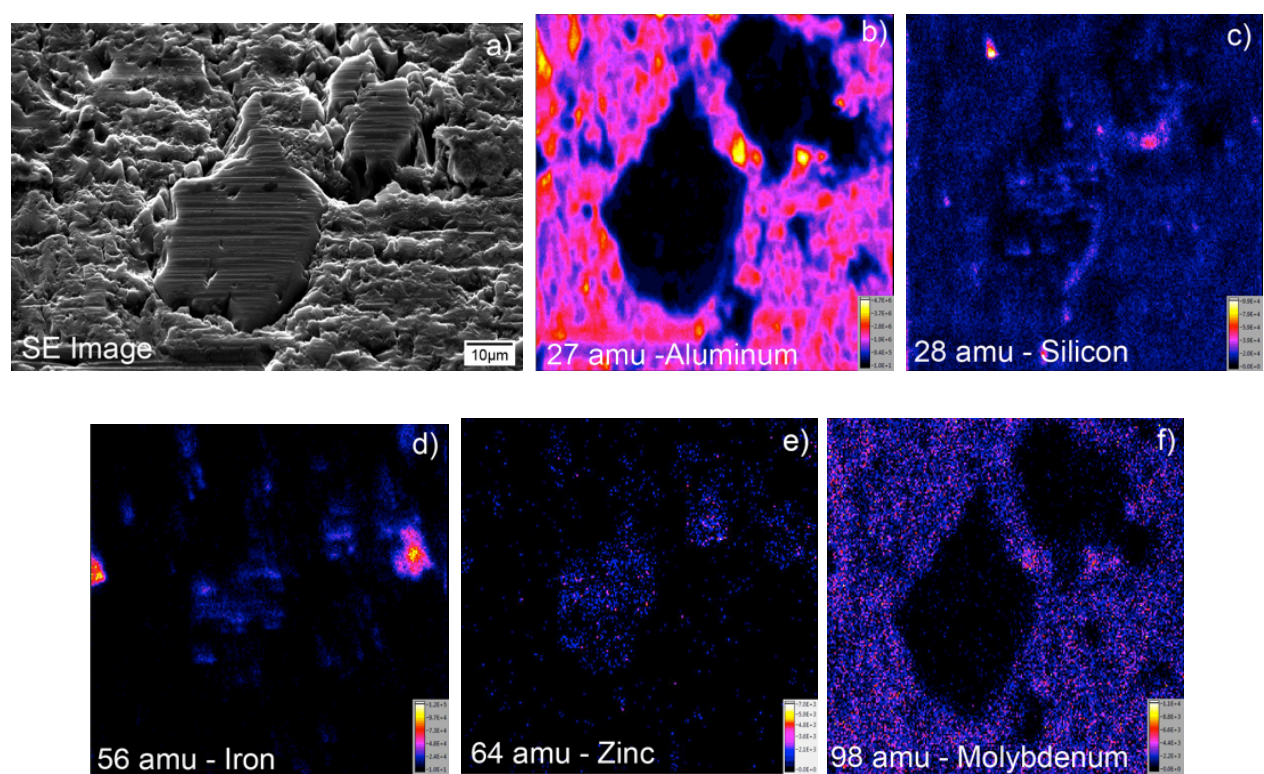

Figure 6. Secondary electron image (a) of surface tribo-films formed on start-stop surface in the midstroke region and (b-f) FIB-SIMS chemical maps of aluminium, silicon, iron, zinc and molybdenum, respectively.
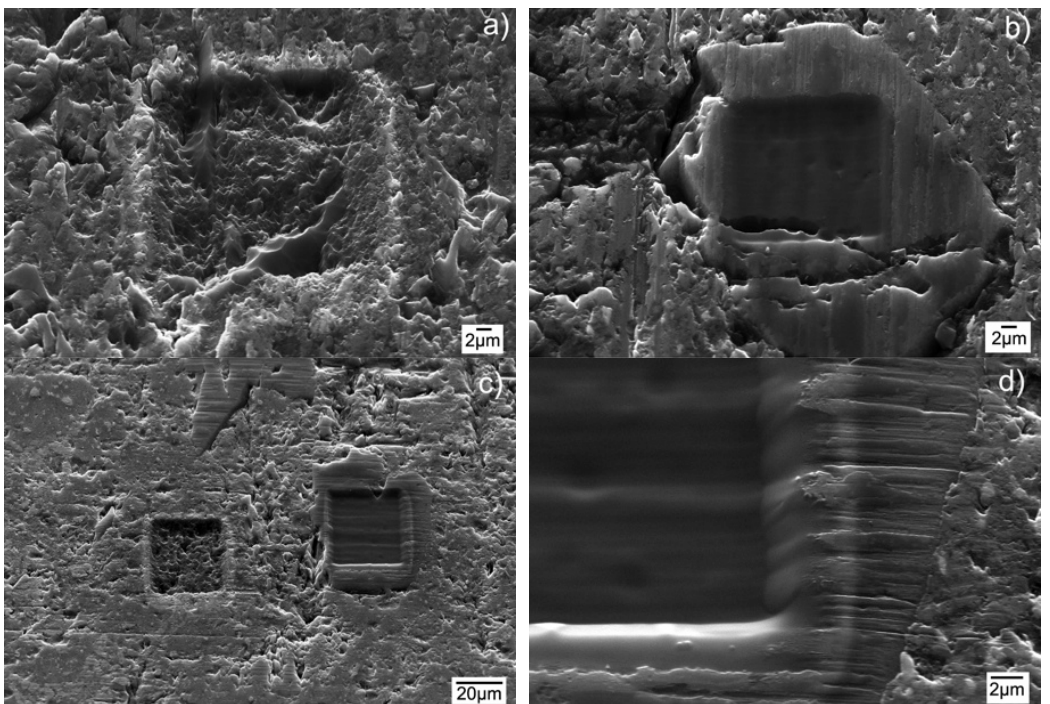

Figure 7. Secondary electron images of FIB-SIMS depth profile craters from aluminium matrix and Si particles from the surface of uninterrupted $(\mathrm{a} \& \mathrm{~b})$ and start-stop $(\mathrm{c})$ tests, respectively. Detail of tribofilm from $\mathrm{c}$ ) is shown in $\mathrm{d})$. 

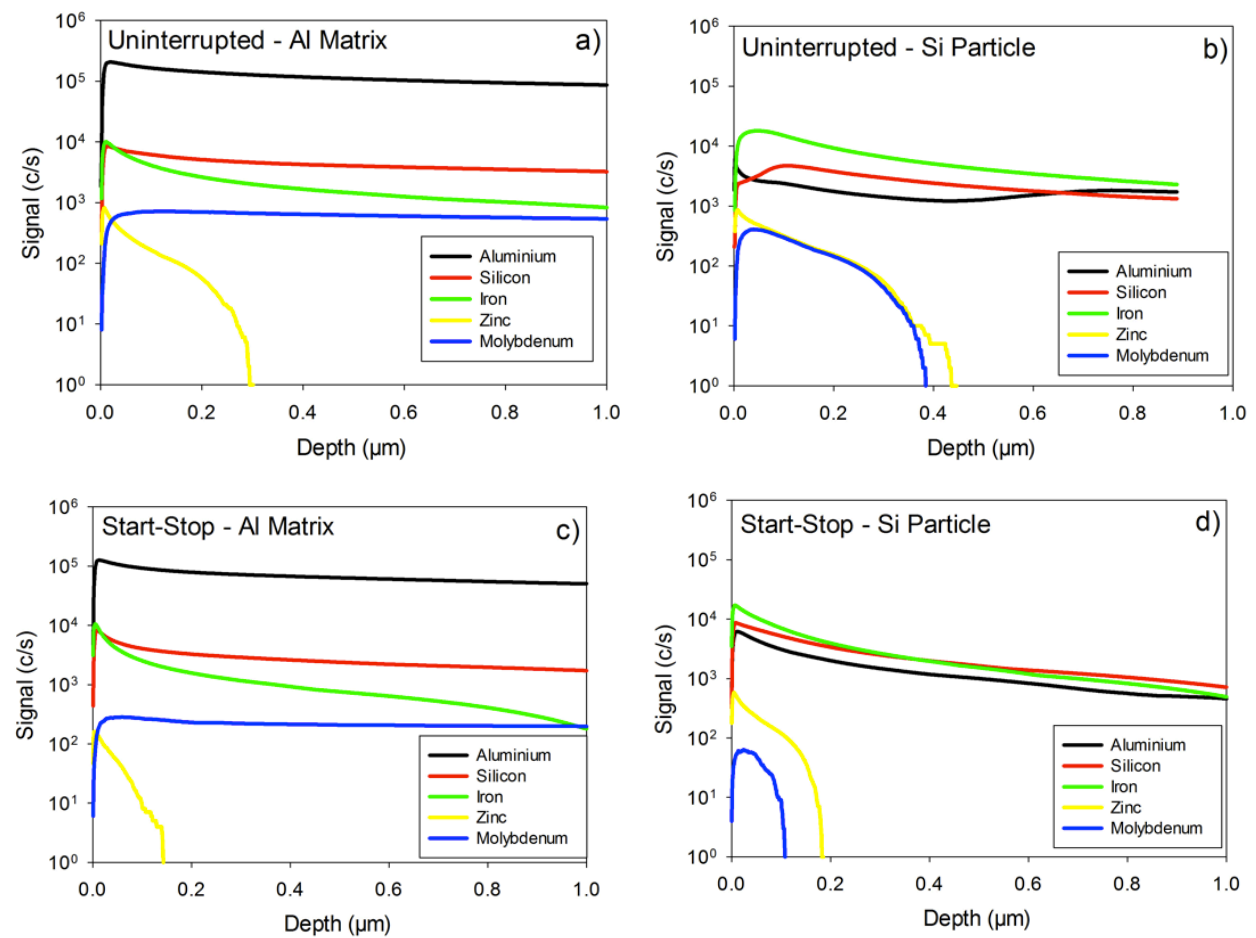

Figure 8. FIB-SIMS depth profiles of the areas indicated in Figure 7.
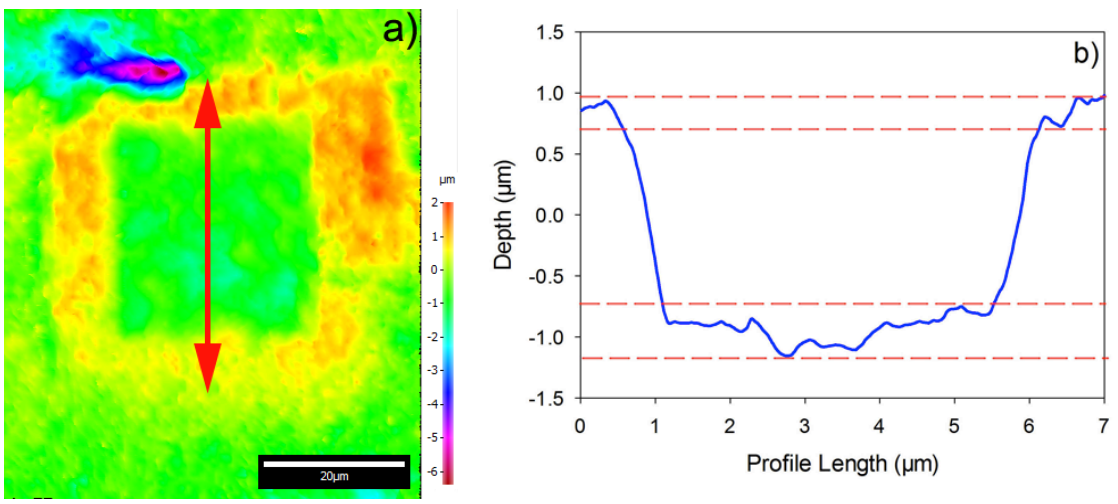

Figure 9. Colour depth map (a) and profile length (b) from FIB-SIMS depth profile of Si particle on uninterrupted sample surface. 
Tables

\begin{tabular}{|c|c|c|c|c|c|c|c|}
\hline $\mathbf{S i}$ & $\mathbf{C u}$ & $\mathbf{M g}$ & $\mathbf{F e}$ & $\mathbf{T i}$ & $\mathbf{Z n}$ & $\mathbf{M n}$ & $\mathbf{A l}$ \\
\hline $16.0-18.0$ & $4.0-5.0$ & $0.5-0.7$ & 0.5 & 0.2 & 0.1 & 0.1 & Balance \\
\hline
\end{tabular}

Table 1. Nominal weight percent composition of A390.

\begin{tabular}{|c|c|c|c|c|c|c|}
\hline $\begin{array}{c}\text { Test } \\
\text { Interval }\end{array}$ & \multicolumn{3}{|c|}{ Uninterrupted Test } & \multicolumn{3}{c|}{ Start-Stop Test } \\
\hline & $\begin{array}{c}\text { Cumulative } \\
\text { Sliding } \\
\text { Distance }(\mathrm{m})\end{array}$ & $\begin{array}{c}\text { Specific Wear } \\
\text { Rate, } \times 10^{-7} \\
\left(\mathrm{~mm}^{3} / \mathrm{Nm}\right)\end{array}$ & $\begin{array}{c}\text { Material } \\
\text { Removal } \\
\text { Rate }(\mathrm{nm} / \mathrm{h})\end{array}$ & $\begin{array}{c}\text { Cumulative } \\
\text { Sliding } \\
\text { Distance }(\mathrm{m})\end{array}$ & $\begin{array}{c}\text { Specific Wear } \\
\text { Rate, } 10^{-7} \\
\left(\mathrm{~mm}^{3} / \mathrm{Nm}\right)\end{array}$ & $\begin{array}{c}\text { Material } \\
\text { Removal } \\
\text { Rate }(\mathrm{nm} / \mathrm{h})\end{array}$ \\
\hline 1 & 3001 & $2.97 \pm 0.14$ & 144 & 2682 & $2.73 \pm 0.05$ & 118 \\
\hline 2 & 7723 & $2.29 \pm 0.10$ & 109 & 5563 & $1.61 \pm 0.03$ & 55 \\
\hline 3 & 17046 & $1.42 \pm 0.02$ & 68 & 11137 & $1.12 \pm 0.03$ & 35 \\
\hline
\end{tabular}

Table 2. Specific wear rates calculated from mass loss data at each test interval.

\begin{tabular}{|c|c|c|c|}
\hline & $\begin{array}{c}\text { Mass Loss } \\
\left(\mathrm{g} \times 10^{-4}\right)\end{array}$ & $\begin{array}{c}\text { Total Sliding } \\
\text { Distance }(\mathrm{m})\end{array}$ & $\begin{array}{c}\text { Mass Loss Rate } \\
\left(\mathrm{g} / \mathrm{m} \mathrm{x} \mathrm{10^{-7 }}\right)\end{array}$ \\
\hline Uninterrupted Test & $32 \pm 0.3$ & 17046 & $1.88 \pm 0.01$ \\
\hline Start-Stop Test & $35 \pm 0.4$ & 11137 & $3.14 \pm 0.04$ \\
\hline
\end{tabular}

Table 3. Total mass loss rates for refined cast iron piston rings.

\begin{tabular}{|c|c|c|}
\hline & $\begin{array}{c}\text { Zn-rich tribo-film } \\
\text { Thickness }(\mathrm{nm})\end{array}$ & $\begin{array}{c}\text { Mo-rich tribo-film } \\
\text { thickness (nm) }\end{array}$ \\
\hline Uninterrupted Matrix & 295 & $>1000$ \\
\hline Uninterrupted Si Particle & 436 & 385 \\
\hline Start-Stop Matrix & 143 & $>1000$ \\
\hline Start-Stop Si Particle & 184 & 108 \\
\hline
\end{tabular}

Table 4. Thickness measurements of $\mathrm{Zn}$ and Mo containing surface tribo-layers 